\title{
ERRATUM
}

\section{Chapter 5 \\ SUSHI: Density Functional Theory Simulator}

\section{Takashi Honda}

(C) Springer Science+Business Media Singapore 2016

Japan Association for Chemical Innovation, Computer Simulation

of Polymeric Materials, DOI 10.1007/978-981-10-0815-3

\section{DOI 10.1007/978-981-10-0815-3_30}

In chapter titled "SUSHI: Density Functional Theory Simulator", Equation 5.61 and Figure 5.5 are incorrect. The correct equation and figure are below:

1. Equation 5.61

Error

$$
\chi N_{A} N_{B}=\frac{1}{2}\left(\frac{N_{A}}{\phi_{A}}+\frac{N_{B}}{\phi_{B}}\right) .
$$

Correct

$$
\chi N_{A} N_{B}=\frac{1}{2}\left(\frac{N_{A}}{\phi_{B}}+\frac{N_{B}}{\phi_{A}}\right) .
$$

The updated original online version for this chapter can be found at DOI 10.1007/978-981-10-0815-3_5 
2. The title of $\mathrm{Y}$ axis of Fig. 5.5

Error
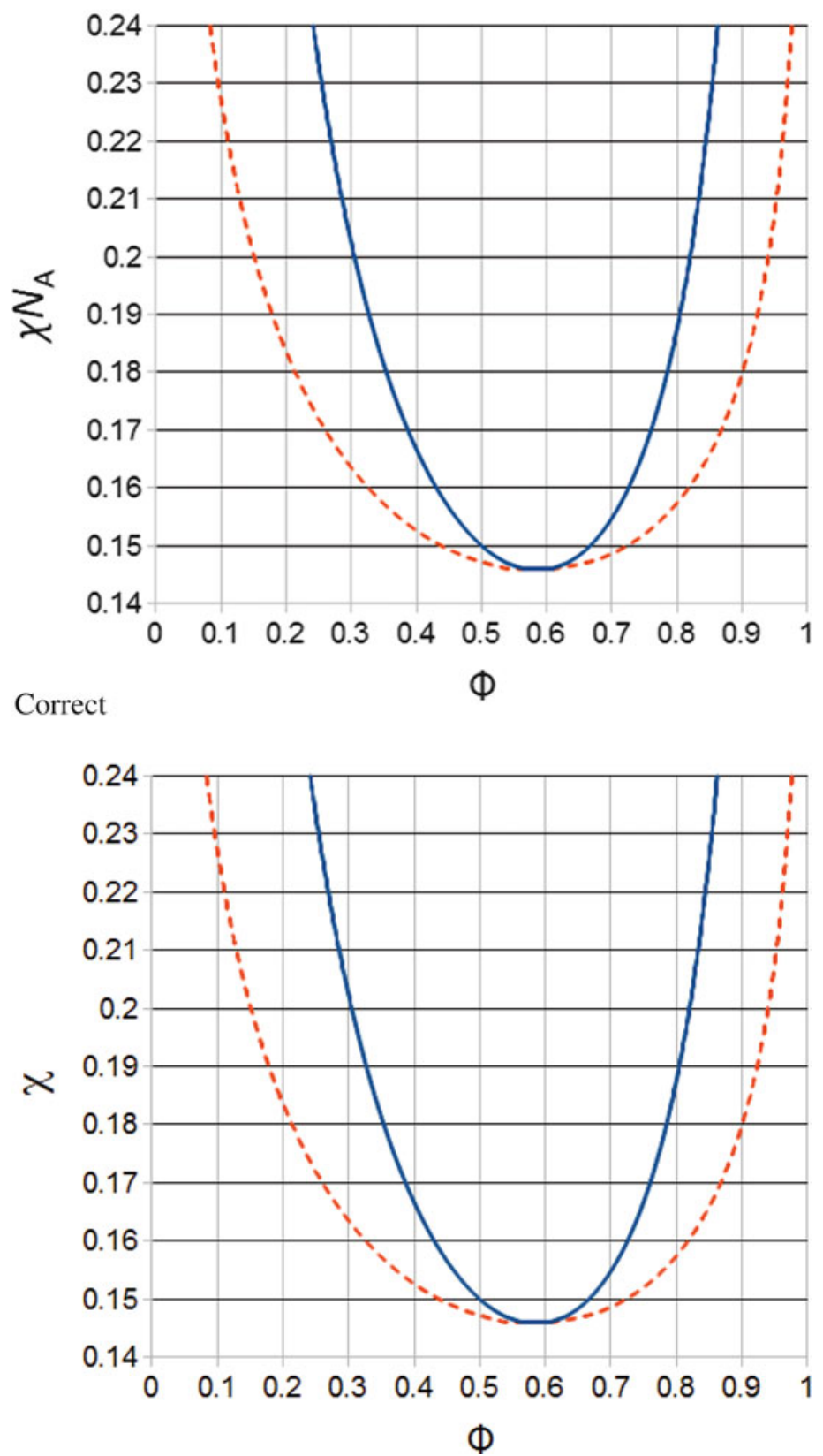